\title{
Comparison Of Estimates Of Proprietary And Syndicated Methods In Auto Industry Surveys
}

Daniel X. Wang

Wang1dx@cmich.edu

Follow this and additional works at: http://digitalcommons.wayne.edu/jmasm

Part of the Applied Statistics Commons, Social and Behavioral Sciences Commons, and the Statistical Theory Commons

\section{Recommended Citation}

Wang, Daniel X. (2003) "Comparison Of Estimates Of Proprietary And Syndicated Methods In Auto Industry Surveys," Journal of Modern Applied Statistical Methods: Vol. 2 : Iss. 1 , Article 18.

DOI: $10.22237 /$ jmasm/1051748280

Available at: http://digitalcommons.wayne.edu/jmasm/vol2/iss1/18 


\title{
Comparison Of Estimates Of Proprietary And Syndicated Methods In Auto Industry Surveys
}

\author{
Daniel X. Wang \\ Department of Mathematics \\ Central Michigan University
}

Proprietary and syndicate surveys are often used in assessing appeal and initial quality of new vehicles for automobile manufactures. This study discusses the difference between the two types of studies, and proposes a computer simulation based method for checking the appropriateness of the comparisons.

Key words: J.D. Power, sample base, pp100 score, initial quality

\section{Introduction}

Quality and assessing quality becomes more and more important issues to the modern automotive industry. The customer survey of J.D. Power and Associates was founded in 1968 as an independent professional information provider for management and it has been considered the most important source for assessing marketing, quality and customer satisfaction.

As one of the important J. D. Power auto surveys, the Initial Quality Study 2 (IQS2) contains comprehensive and analytically rich information that can help auto manufacturers position their image and products. Consumers of new vehicles are surveyed regarding problems they experienced after 90 days of vehicle ownership. All the problems are weighted equally and the result is summarized with problems per 100 vehicles. The pp100 scores are compared across models and platforms, by manufacturer and assembly plants. The survey contains 135 problems (since 1998) and over nine categories.

Daniel Wang is an Assistant Professor of Statistics at Central Michigan University. He graduated from the University of Alabama with a Ph. D. in Applied Statistics in 1999. He worked at the Biostatistics Unit at the University of Alabama as a Ph.D. fellow and was a statistical consultant at Mercedes Benz, US International. E-mail him at: Wang1dx@cmich.edu.
Auto manufacturers highly regard the results of J. D. Power auto surveys as a measure of their performance in terms of quality, service and customer's satisfaction. Toyota considers that J. D. Power and Associates is the most respectable name in auto consumers' minds and its IQS has been the industry standard benchmark for vehicle quality since 1987 . Auto manufacturers would like to mention their achievement recognized through the surveys by J.D. Power and Associates. For example "Corolla was the highest ranked Compact Car in the J.D. Power and Associates' 2000 Initial Quality Study. Study based on a total of 47,909 consumer responses indicating owner-reported problems during the first 90 days of ownership (Spring 2002 www.toyota.com)". "Expedition shines when it comes to Initial Quality. The Expedition ranked as the Best Full-Size Sport Utility Vehicle in Initial Quality in the J.D. Power and Associates 2001 Initial Quality Study based on a total of 54,565 consumer responses indicating owner reported problems during the first 90 days of ownership (Spring 2002, www.ford.com)."

Figure 1 is an example of IQS results, which give the industrial performance for the total of 36 manufacturers (Spring 2002, www.auto.com). 
Figure 1

Example of J. D. Power IQS2 by Mark with 175 Models

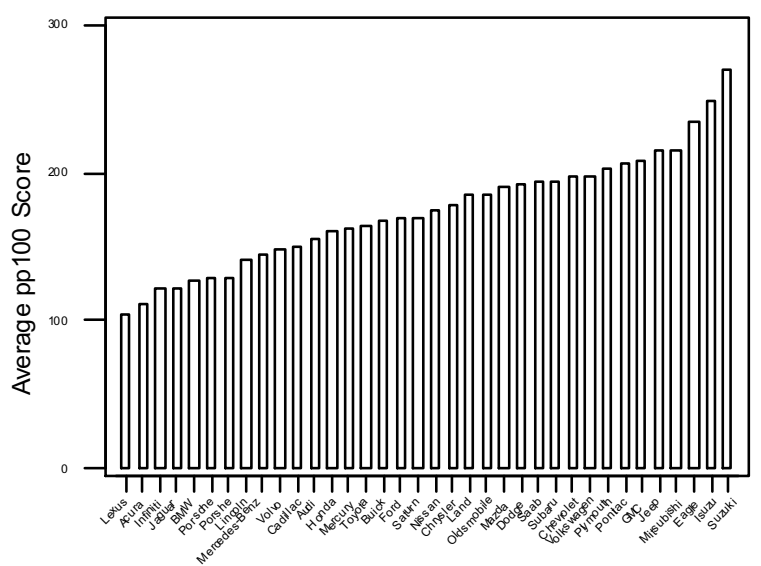

In order to monitor the continuous quality improvement and to forecast the IQS results, manufacturers often conduct proprietary studies similar to the IQS study through J.D. Power \& Associates monthly or quarterly. However, due to the effect of many factors of sampling methods, the comparison of the two types of studies is questionable. For example a random sample is used for the IQS study while a stratified random sample is used for the IQS study. Other factors may include different periods for reporting problems, sample size of vehicles, complete sample base and incomplete sample base. A valid comparison cannot be made without appropriately addressing these issues. This article focuses on comparing the results using two different sampling methods. Concerns about partial sample base and complete sample base are also discussed.

\section{Methodology}

The two different sampling methods used in auto surveys of J. D. Power and Associates are introduced in this section with the notations and derived estimates.

\section{Syndicated Study and Proprietary Study}

The syndicated survey is a number of studies of automobiles conducted by J.D. Power and Associates independently. The results of these studies are published and the detail results for a specific model may be sent to the manufacturer. The detail results can be analyzed for quality and customer's satisfaction improvement, especially for manufacturers who believe the philosophy that customer should determine what they want and what they like. The Appeal Study by J.D. Power Associates is also used for assessing customer's satisfaction.

Proprietary survey is the studies, which are usually similar to J.D. Power study conducted by J.D. Power and Associates but upon the request of a manufacturer. In addition to the syndicated studies, the proprietary studies are considered as a continuous monitor of the product performance. Further the results are used for forecasting the future J.D. Power score. Instead of the three month time period for reporting problems for customers in the syndicated study, the time period for the proprietary study may vary. For example it could be one month or two months depending on the manufacture's interest.

Two different sampling methods have been used in the two types of auto survey. For the syndicated survey such as IQS study, stratified samples are drawn from the same model of vehicles, because minimum sample size is required for a model. Usually about $30 \%$ of the registrations for the total leased vehicles are nt available for J.D. Power. Therefore using a stratified sample can help to obtain a desired number of vehicles in the sample, which include both purchased and leased vehicles. On the other hand, for the proprietary survey the manufacturers usually provide all possible registrations for the purchased and the leased vehicles. So a random sample is used for the proprietary study. Figure 2 gives a typical example of the IQS2 scores sampled using different methods in different time periods for a type of vehicle.

When a result of proprietary study is compared to the syndicated study, there are some concerns about how the difference of the sampling bases, and different sample methods and different time period for reporting problems. This study focuses on the discussion of comparing the two sampling methods given the same sample base, then discusses the results for the case of having different sample bases, which simulates the situation of the syndicated study without part of leased vehicles versus the proprie tary study with full sample base. 
Figure 2

J. D. Power Results for M-Class

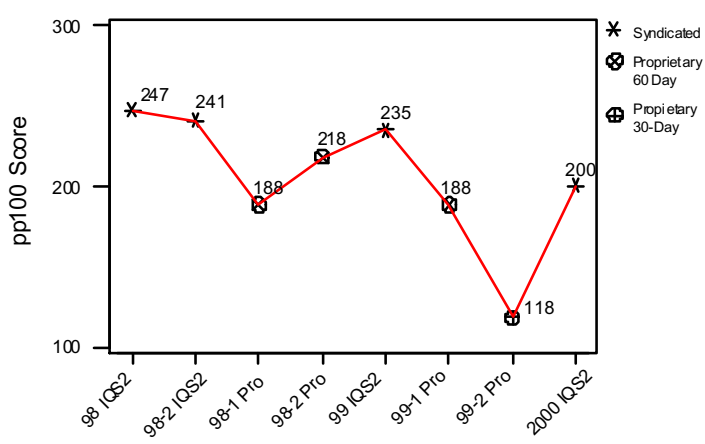

Estimates

Suppose a stratified sample is drawn for the syndicated study with size $n$, then $n=n_{P}+n_{L}$ where $n_{P}$ is the number of purchased vehicles and $\mathrm{n}_{\mathrm{L}}$ is the number of leased vehicles in the sample. The estimated pp100 score the estimated as

$$
\begin{aligned}
\hat{S}_{p p 100} & =\frac{100\left(\frac{N_{P}}{n_{P}} \sum_{i=1}^{n_{p}} X_{i}^{P}+\frac{N_{L}}{n_{L}} \sum_{j=1}^{n_{L}} X_{j}^{L}\right)}{N} \\
= & \frac{100\left(N_{P} \bar{X}^{P}+N_{L} \bar{X}^{L}\right)}{N}
\end{aligned}
$$

where $\mathrm{N}=\mathrm{N}_{\mathrm{P}}+\mathrm{N}_{\mathrm{L}}$ is the total number of vehicles sampling from, $\mathrm{N}_{\mathrm{P}}$ and $\mathrm{N}_{\mathrm{L}}$ are the total numbers for the purchased and the leased. $\frac{N_{P}}{n_{P}}$ and $\frac{N_{L}}{n_{L}}$ are the weights for the number of problems for the purchased vehicle $\mathrm{X}_{\mathrm{i}}^{\mathrm{P}}$ and the leased vehicle $\mathrm{X}_{\mathrm{j}}^{\mathrm{L}}$. Suppose the true average number of problems per vehicle for the purchased and the leased are $\mu_{\mathrm{P}}$ and $\mu_{\mathrm{L}}$, then the estimate of the true pp100 score is

$$
\begin{aligned}
E\left(\hat{S}_{p p 100}\right) & =\frac{100\left(N_{P} E\left(\bar{X}^{P}\right)+N_{L} E\left(\bar{X}^{L}\right)\right)}{N}, \\
& =\frac{100\left(N_{P} \mu_{P}+N_{L} \mu_{L}\right)}{N}
\end{aligned}
$$

which is the weighted true pp100 score for the vehicles. The variance of $\hat{S}_{\mathrm{pp} 100}$ is

$$
\begin{aligned}
\operatorname{Var}\left(\hat{\mathrm{S}}_{\mathrm{pp} 100}\right) & =\operatorname{Var}\left(\frac{100\left(\mathrm{~N}_{\mathrm{P}}\left(\overline{\mathrm{X}}^{\mathrm{P}}\right)+\mathrm{N}_{\mathrm{L}}\left(\overline{\mathrm{X}}^{\mathrm{L}}\right)\right)}{\mathrm{N}}\right) \\
& =\frac{100^{2}\left(\mathrm{~N}_{\mathrm{P}}^{2} \sigma_{\mathrm{P}}^{2}+\mathrm{N}_{\mathrm{L}}^{2} \sigma_{\mathrm{L}}^{2}\right)}{\mathrm{N}^{2}}
\end{aligned}
$$

For the proprietary study, suppose a random sample is drawn with size n. The pp100 score is notated as follows using the same type of notation.

$$
\begin{aligned}
\hat{S}_{p p 100} & =\frac{100\left(\sum_{i=1}^{n_{p}} X_{i}^{P}+\sum_{j=1}^{n_{L}} X_{j}^{L}\right)}{n} \\
= & \frac{100}{n}\left(n_{p}^{*} \bar{X}^{P}+n_{L}^{*} \bar{X}^{L}\right)=100 \bar{X}
\end{aligned}
$$

and

$$
\begin{aligned}
E\left(\hat{S}_{p p 100}\right) & =E(100 \bar{X})=100 \mu \\
& =\frac{100\left(N_{P} \mu_{P}+N_{L} \mu_{L}\right)}{N}
\end{aligned}
$$

where $\mu$ is the true average number of problems per vehicle for all vehicles including both purchased and the leased. Since this is a random sample, both sample sizes for purchased $\mathrm{n}_{\mathrm{P}}^{*}$ and leased group $\mathrm{n}_{\mathrm{L}}^{*}$ are also random and they are correlated, because $n=n_{P}^{*}+n_{L}^{*}$. Therefore given the same sample base, both estimates of pp100 scores for the two studies have the same mean, and they are unbiased. For the proprietary study, the variance can be denoted as

$$
\operatorname{Var}\left(\hat{S}_{\mathrm{pp} 100}\right)=\operatorname{Var}(100 \overline{\mathrm{X}})=\frac{100^{2} \sigma^{2}}{\mathrm{n}}
$$

where $\sigma^{2}$ is the true variance for the number of problems per vehicle for all vehic les. This means the two studies give the unbiased estimates with different variances.

If $30 \%$ of leased vehicles are excluded from the sample base due to certain reason, for 
example the registration information is not available at the sampling time period, the parameters of the sample base $\mu_{L}, \sigma_{L}, \mu$ and $\sigma$ are affected. So the estimates of pp100 scores will depend on how the samples are excluded for the leased base.

\section{Results}

It is clear that theoretically comparing the results of the two different surveys is impossible since too many assumptions have to be made about the unknown parameters. Especially for the proprietary sampling, the sample sizes for the purchased $\mathrm{n}_{\mathrm{P}}^{*}$ and for the leased group $\mathrm{n}_{\mathrm{L}}^{*}$ are random and they are correlated, but in the syndicated sampling they are both constant. Based on the discussion in the previous section, applied approaches are proposed to investigate the two sampling methods.

For a specific model of vehicle, a computer simulation is used with a simulated sample base. The sample base can be built using existing J.D. Power data as a good approximation to the real sample base. Then exclude $30 \%$ or as desired portion of vehicles from the full base to obtain an approximation to sample base similar to the one used in the syndicated study. The next step is to write computer programs or macros for the syndicated study and the proprietary study, then apply them a large number of times to the sample bases built. Comparisons for two studies can be made based on the simulated results.

A sample base for the proprietary study can be built using existing information, which could be from a published source or data for a model of vehicles if the study is conducted for an auto manufacturer. First chose the size of sample base $N$ with $N_{L}$ for the leased and $N_{P}$ for the purchased. Then determine the proportions for the vehicles to have 0 problems to 12 problems, which is the maximum number of problems used in the IQS2 of J.D. Power and Associates. The problems can be also attributed to the nine different categories. Finally form the sample base for the syndicated study by excluding a proportion, for example $30 \%$ of leased vehicles from the sample base for the proprietary study.

As an example, using the IQS2 1998 (J.D. Power, 2001 Knight Ridder Inc.) result for MClass, a sample base with following characteristics (see Table 1), where the mean is the mean number of problems per vehicle. The above sample base is for the proprietary study and it can be considered a good approximation of the M-Class registered during the sampling period of 1998 J.D. Power IQS2 study. Now randomly exclude $30 \%$ of vehicles from the le ased vehicles, the sample base for the syndicate study of J.D. Power is made with the following statistical summaries (see table).

The structure of the sample base is hypothetical to allocate the proportion of the number of problems from 0 to 12 to all vehicles. The proportions for a specific model of vehicle can be obtained from the actual J. D. Power survey.

Two Minitab macros, one for the syndicated study and the other for the proprietary study are created for the simulations. 5,000 simulations are run for each of the two sampling methods, and for each of the full and partial sample bases. For each combination of sampling method and sampling base, the weighted and notweighted pp100 scores are reported. The results are shown in Table 3 (on next page) and are also presented as in the following distribution dot plots on the same scale. See figure 3 (next page).

Table 1

Descriptive Statistics for the Full Sample Base

\begin{tabular}{|lcc|lcll|}
\hline Variable & $\mathrm{N}$ & Mean & Median & StDev & Minimum & Maximum \\
\hline Purch.\&Leas & 7760 & 2.4647 & 2.0000 & 2.5267 & 0.000 & 12 \\
\hline Purchased & 5807 & 2.3337 & 2.0000 & 2.4395 & 0.000 & 12 \\
\hline Leased & 1953 & 2.8541 & 2.0000 & 2.6965 & 0.000 & 11 \\
\hline
\end{tabular}


Table 2

Descriptive Statistics for Partial Sample Base without $30 \%$ of Leased Vehicles

\begin{tabular}{|lcl|llll|}
\hline Variable & $\mathrm{N}$ & Mean & Median & StDev & Minimum & Maximum \\
\hline Purch.\&Leased & 7174 & 2.4295 & 2.0000 & 2.4874 & 0.000 & 12 \\
\hline Purchased & 5807 & 2.3337 & 2.0000 & 2.4395 & 0.000 & 12 \\
\hline Leased & 1367 & 2.8361 & 2.0000 & 2.6440 & 0.000 & 11 \\
\hline
\end{tabular}

Figure 3
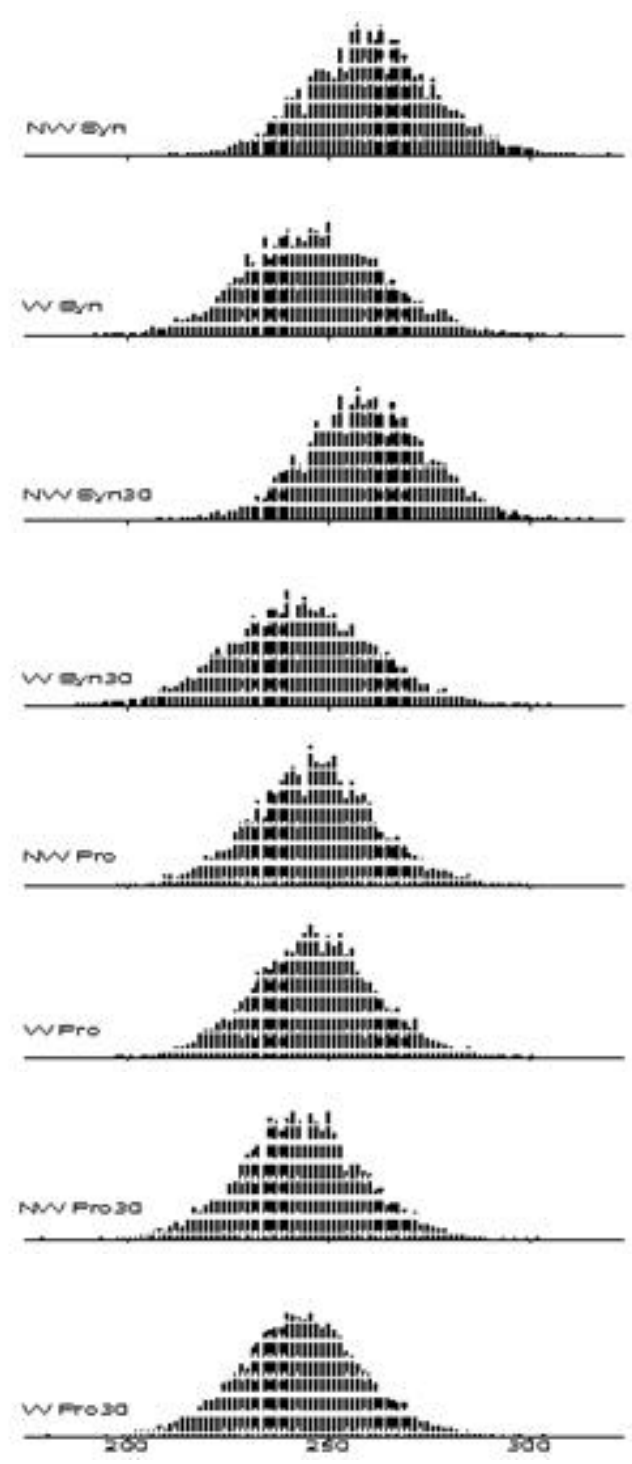

Conclusion

Based on the discussions and the results the computer simulations with the examples in previous sections, the comments and recommendations are made as the following.

For the same sample bases, both the syndicate and proprietary studies give the same accurate estimates of the true pp100 score on the average. But the syndicate sampling method tends to have larger variation for the estimated score. This means that the syndicated sampling method introduces extra variation into the sample scores.

Table 3

Summary of the Simulations W/NW: Weighted/Not weighted

F/P: Full Sample Base/Partial Sample Base

\begin{tabular}{lccccc}
\hline & W/ & F/P & $\begin{array}{c}\text { Simulated } \\
\text { pp100 Score }\end{array}$ & $\begin{array}{c}\text { True } \\
\text { pp100 }\end{array}$ & StDer \\
& NW & F & 260.47 & 246.47 & 15.23 \\
& W & F & 246.50 & 246.47 & 16.90 \\
$\begin{array}{l}\text { Syndicated } \\
\text { Study }\end{array}$ & N & P & 259.42 & 242.95 & 14.96 \\
& W & P & 242.91 & 242.95 & 17.56 \\
\hline & N & F & 246.41 & 246.47 & 14.91 \\
$\begin{array}{l}\text { Proprietary } \\
\text { Study }\end{array}$ & W & F & 246.40 & 246.47 & 14.89 \\
& N & P & 243.03 & 242.95 & 14.72 \\
& W & P & 243.02 & 242.95 & 14.76 \\
\hline
\end{tabular}

Therefore the syndicate study gives a less accurate sample score than that of the proprietary method. Even though this simulation does not provide in general by how much the variation is between the two sampling methods, it does provide informative details for comparing the results from different sampling methods for a particular model of an auto manufacturer. For example when the manufacturer compares the results from two sampling methods, the variation due to using 
syndicated sampling can be assessed with the simulation results.

The $30 \%$ exclusion of leased vehicles has some impact on the average score and this impact is significant depending on number and the way vehicles are excluded. The partial sample base introduces additional variation into the syndicated study. In general this is expected, but the simulation gives specific results. If the manufacturer has some knowledge about excluding the leased vehicles, then that can be put into the simulation to get more details about the effect of using partial sample base.

For the proprietary study, both the weighted and the not-weighted scores are the same since random samples are used. But for the syndicated study they are different because stratified random samples are used. This helps the management of an auto manufacturer to understand the "weight" used in syndicated studies of J. D. Power and Associates.

Finally, when comparing the syndicate and the proprietary studies, it is necessary to consider the effect of the variation due to using different sampling methods and different sample bases, especially for monitoring the on-going performance of an auto manufacturer through J.D. Power auto survey. The proposed simulation method can be adapted to a particular model for which both syndicated and proprietary surveys are available. The computer macros can be easily modified for carrying out the simulations. After assessing the variation attributed to the sampling methods and sample base, manufacturers can appropriately compare the pp100 scores of their products.

Clearly, it would be better for the manufacturers to have the proprietary study conducted in the same way as the syndicated study. Although different sample bases are used for the two studies, the extra variation in estimating the pp100 score will be coming from just one source instead of two sources. It is important to get as many details as possible for the proprietary study.

Comparing the pp100 scores with different reporting time periods is worth further study. The reason for auto manufacturers to have one or two month surveys is because the short time studies provide quick response. If the proprietary study is conducted using different time periods for reporting problems (one or two months), comparing the pp100 scores to that of two months or three months is more complicated because an extra source of variation is introduced. Manufacturers multiply a weight to the one-month or two-month proprietary scores and then compare them to the three-month scores. The weight may be obtained from J. D. Power, for example 70\% percent of problems associated with new vehicles are usually reported in the first two months.

\section{References}

Alwin, D. F. (1991). Research on survey quality. Sociological Methods and Research, 20, 3-29.

Babbie, E. R. (1973). Survey research methods. Belmont, CA: Wadsworth.

Biemer, P., \& R. Caspar. (1994). Continuous quality improvement for survey operations: Some general principles and applications. Journal of Official Statistics, 10, 307-326.

Breiman, L. (1994). The 1991 census adjustment: Undercount or bad data? Statistical Science, 9, 458-475.

Brewer, K. R. W. (1963). Ratio estimation and finite populations: Some results deducible from the assumption of an underlying stochastic process. Australian Journal of Statistics, 5, 93105.

Bureau of Labor Statistics, Handbook of Methods, vols. I \& II, (1982). Washington, DC: U.S. Department of Labor.

Campbell, C., \& Joiner, B. (1973). How to get the answer without being sure you asked the question. American Statistician, 27, 229-231.

Cornfield, J. (1944). On samples from finite populations. Journal of the American Statistical Association, 39, 236-239.

Dalenius, T. E. (1981). The survey statistician's responsibility for both sampling and measurement errors. In D. Krewski, R. Platek, \& J. N. K. Rao (Eds.) Current topics in survey sampling, 17-29. New York, Academic Press.

Deming, W. E. (1950). Some theory of sampling. NY, Dover. 
Deming, W. E., \& Stephan, F. F. (1940). On a least squares adjustment of a sample frequency table when the expected marginal totals are known. Annals of Mathematical Statistics, 11, 427-444.

Godambe, V. P. (1955). A unified theory of sampling from finite populations. Journal of the Royal Statistician Society, Ser B., 17, 269-278.

J. D. Power \& Associates. Explore our studies and awards. www.jdpa.com/studies/

Jones, H. L. (1956). Investigation of the properties of a sample mean by employing random subsample means. Journal of the American Statistical Association, 51, 54-83.

Kish, L. (1965). Survey sampling. NY: Wiley.

Kover, J. G., Rao, J. N. K., \& Wu, C. F. J. (1988). Bootstrap and oher methods to measure errors in survey estimates. Canadian Journal of Statistics 16 (suppl.), 25-45.

Parten, M. (1950). Surveys, polls, and samples: Practical procedures. NY: Harper \& Brothers.
Raj, D. (1968). Sampling theory. NY: McGraw-Hill.

Rao, J. N. K., Hartley, H. O., \& Cochran, W. G., (1962). A simple procedure for unequal

probability sampling without replacement. Journal of the Royal Statistician Society, Ser. B, 24, 482-491.

Sudman, S. (1976). Applied Sampling. NY: Academic Press.

Toyota Quality - Satisfaction. (2002). ww.toyota.com/html/shop/distinct/satisfaction/ind ex.html

Waksberg, J. (1978). Sampling methods for random digit dialing. Journal of the American Statistical Association, 73, 40-46.

Williams, B. (1978). A Sampler on Sampling. NY: Wiley.

Yates, F. (1946). A review of recent statistical developments in sampling and sampling surveys. Journal of the Royal Statistical Society, 109, 12-30. 